\title{
Is hip fracture surgery safe for patients on antiplatelet drugs and is it necessary to delay surgery? A systematic review and meta-analysis
}

\author{
Zhanyu Yang, Jiangdong Ni*, Ze Long, Letian Kuang, Yongquan Gao and Shibin Tao
}

\begin{abstract}
Background: Hip fractures are common and account for a large proportion of orthopedic surgical admissions in elderly patients. However, determining the timing for surgery has been controversial for patients who develop hip fractures while on antiplatelet treatment.

Methods: Computerized databases for studies published from the inception date to January 2020, including the Cochrane Library, PubMed (Medline), EMBASE, Web of Science ${ }^{T M}$, ClinicalTrials, ClinicalKey, and Google Scholar, were searched using the keywords "Hip AND Fracture", "Antiplatelet", "Antithrombocyte", "Platelet aggregation inhibitors", "Aspirin", "Plavix", and "Clopidogrel".

Results: In total, 2328 initial articles were identified. Twenty-four studies with 5423 participants were ultimately included in our analysis. Early surgery was associated with an increased transfusion rate in the antiplatelet group compared to the non-antiplatelet group (OR $=1.21 ; 95 \% \mathrm{Cl}, 1.01$ to $1.44 ; p=0.03)$. Early surgery for hip fracture patients on antiplatelet therapy was associated with a greater decrease in hemoglobin compared to delayed surgery (WMD $=0.75 ; 95 \% \mathrm{Cl}, 0.50$ to 1.00; $p<0.001)$. However, early surgery appeared to decrease the length of hospitalization $(\mathrm{WMD}=-6.05 ; 95 \% \mathrm{Cl}$, 7.06 to $-5.04 ; p<0.001)$ and mortality ( $\mathrm{OR}=0.43 ; 95 \% \mathrm{Cl}, 0.23$ to $0.79 ; p=0.006)$.

Conclusion: It is unnecessary to delay surgery to restore platelet function when patients with hip fractures receive antiplatelet therapy. Furthermore, early surgery can significantly reduce mortality and hospital stay, which is conducive to patient recovery. Future randomized trials should determine whether the results are sustained over time.
\end{abstract}

Keywords: Hip fractures, Meta-analysis, Platelet aggregation inhibitors, Aspirin

\section{Background}

Hip fractures are among the main causes of orthopedic surgical admissions and life-threatening injuries that occur worldwide, mainly in elderly individuals. Older patients are particularly vulnerable to sustaining hip fractures because of the high prevalence of

\footnotetext{
* Correspondence: nijiangdong001@csu.edu.cn
Department of Orthopaedics, The Second Xiangya Hospital, Central South

* Correspondence: nijiangdong001@csu.edu.cn
Department of Orthopaedics, The Second Xiangya Hospital, Central South University, No. 139 Renmin Street, Changsha, Hunan 410000, People's Republic of China
}

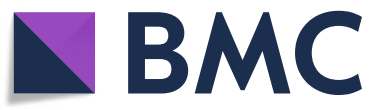

(c) The Author(s). 2020 Open Access This article is licensed under a Creative Commons Attribution 4.0 International License, which permits use, sharing, adaptation, distribution and reproduction in any medium or format, as long as you give appropriate credit to the original author(s) and the source, provide a link to the Creative Commons licence, and indicate if changes were made. The images or other third party material in this article are included in the article's Creative Commons licence, unless indicated otherwise in a credit line to the material. If material is not included in the article's Creative Commons licence and your intended use is not permitted by statutory regulation or exceeds the permitted use, you will need to obtain permission directly from the copyright holder. To view a copy of this licence, visit http://creativecommons.org/licenses/by/4.0/. The Creative Commons Public Domain Dedication waiver (http://creativecommons.org/publicdomain/zero/1.0/) applies to the data made available in this article, unless otherwise stated in a credit line to the data.

osteoporosis or osteopenia. According to the American Academy of Orthopaedic Surgeons, each year, the number of hospital admissions due to hip fractures can reach up to 350,000 [1]. By the year 2040, there will be more than 500,000 people with hip fractures per year, with an annual medical expenditure of at least $\$ 9.8$ billion [1,2]. Although the development of surgical instruments and medical technology for early mobilization has advanced significantly, the mortality rate remains high. The cause of this high mortality 
rate is not entirely clear, and most of the deaths are ascribed to comorbidities, including cardiovascular disease [3, 4]. Antiplatelet drugs are simultaneously used in most hip fracture patients for primary and secondary prevention of cardiovascular or cerebrovascular events. Because the inhibitory action of drugs on platelets is irreversible and mature platelets do not synthesize new proteins, antiplatelet drugs make platelets ineffective for approximately 7 days, the mean lifetime of a platelet [5].

Despite the obvious advantages in the prevention and treatment of cardiovascular diseases, the continued use of antiplatelet drugs perioperatively may have great risks. Clopidogrel therapy in cardiac surgery without preoperative disruption increased hemorrhagic risks, transfusion demands, and infection with a poor prognosis [6]. The potential hematoma risk in orthopedic surgery [7] forces the withdrawal of antiplatelet drugs and delays surgery for at least 5 days to allow platelet function to return to an adequate status. Currently, no agreed upon guidelines exist for the appropriate surgical time for patients suffering hip fractures while on antiplatelet therapy, and there is a marked divergence of opinion on the final results of early and delayed surgical intervention [8].

Therefore, the purpose of this review was to identify whether early surgical intervention can be safely implemented on patients who develop hip fractures while on antiplatelet therapy to promote satisfactory outcomes. A secondary aim was to determine whether early or delayed surgery was more appropriate for those patients. Moreover, we attempt to establish a framework for managing hip fracture patients with antiplatelet therapy.

\section{Methods}

\section{Literature search}

This review was performed in accordance with the Preferred Reporting Items for Systematic Review and Meta-Analysis statement (PRISMA) [9]. The following databases were fully searched from their inception date to January 2020: PubMed, EMBASE, the Cochrane Library, Web of Science ${ }^{\mathrm{TM}}$, ClinicalTrials, ClinicalKey, and Google Scholar. For each database, a specific search strategy was developed using the following keywords: "Hip AND Fracture", "Antiplatelet", "Antithrombocyte", "Platelet aggregation inhibitors", "Aspirin", "Plavix", and "Clopidogrel" (detailed search strategies as shown in Additional file). Searches were without date or geographic restriction but were limited to primary studies written in English. All references of retrieved articles were also checked for additional relevant studies.

\section{Inclusion and exclusion criteria}

Studies were included according to the following inclusion criteria: (1) randomized-controlled trials or highquality observational studies; (2) studies that compared the use of antiplatelet drugs on admission with placebo or no treatment in hip fracture patients undergoing early surgery (the time from admission to theater $<5$ days); and (3) studies that compared early surgery $(<5$ days $)$ with delayed surgery ( $>5$ days) for patients suffering hip fractures while on antiplatelet therapy. Based on previous studies and half-life of antiplatelet drugs, we set 5 days as the dividing line. The exclusion criteria were as follows: (1) studies comparing non-antiplatelet medication, such as warfarin or low molecular weight heparin; (2) non-clinical studies such as basic science studies, narrative reviews, surveys, letters, editorials, case series, case reports, comments, conference abstracts, or expert opinions; and (3) non-English studies. The potential overlap of subjects was evaluated by comparing demographic characteristics when multiple studies were conducted by the same author or research institute. Titles and abstracts were filtered and evaluated independently in a non-blinded standardized pattern. A final decision was made based on the adherence to the inclusion and exclusion criteria. Divergence was resolved by consensus.

As shown in Fig. 1, from the search, 2328 potentially eligible records were identified (including duplicates), 137 studies from The Cochrane Library, 318 studies from PubMed, 1421 studies from EMBASE, 445 studies from Web of Science ${ }^{\mathrm{TM}}$, 1 study from ClinicalTrials, 3 studies from ClinicalKey, and 3 studies from Google Scholar. Removal of duplicates left 1625 articles. Of those studies, 1587 were excluded after their titles and abstracts were screened. The remaining 38 studies were read in full for eligibility. No additional studies were found from the references of the retrieved studies. Fourteen studies were eliminated for the following reasons: 4 studies with concurrent treatment with non-antiplatelet drugs; 1 study not reporting the time from admission to surgery; 3 studies comparing non-antiplatelet medication; and 6 studies in which grouping did not meet the inclusion criteria. The reasons for exclusion are listed in Table 1. Eventually, 24 studies were included in this review.

\section{Assessment of study quality}

No relevant randomized-controlled trials were detected; all of the included studies were comparative cohort studies in design. Therefore, the quality of the included studies was evaluated by the Newcastle/Ottawa scale (NOS) [24]. Two investigators independently scored items and assessed bias blinded to the study outcome. For each item, different response options were available, and a 


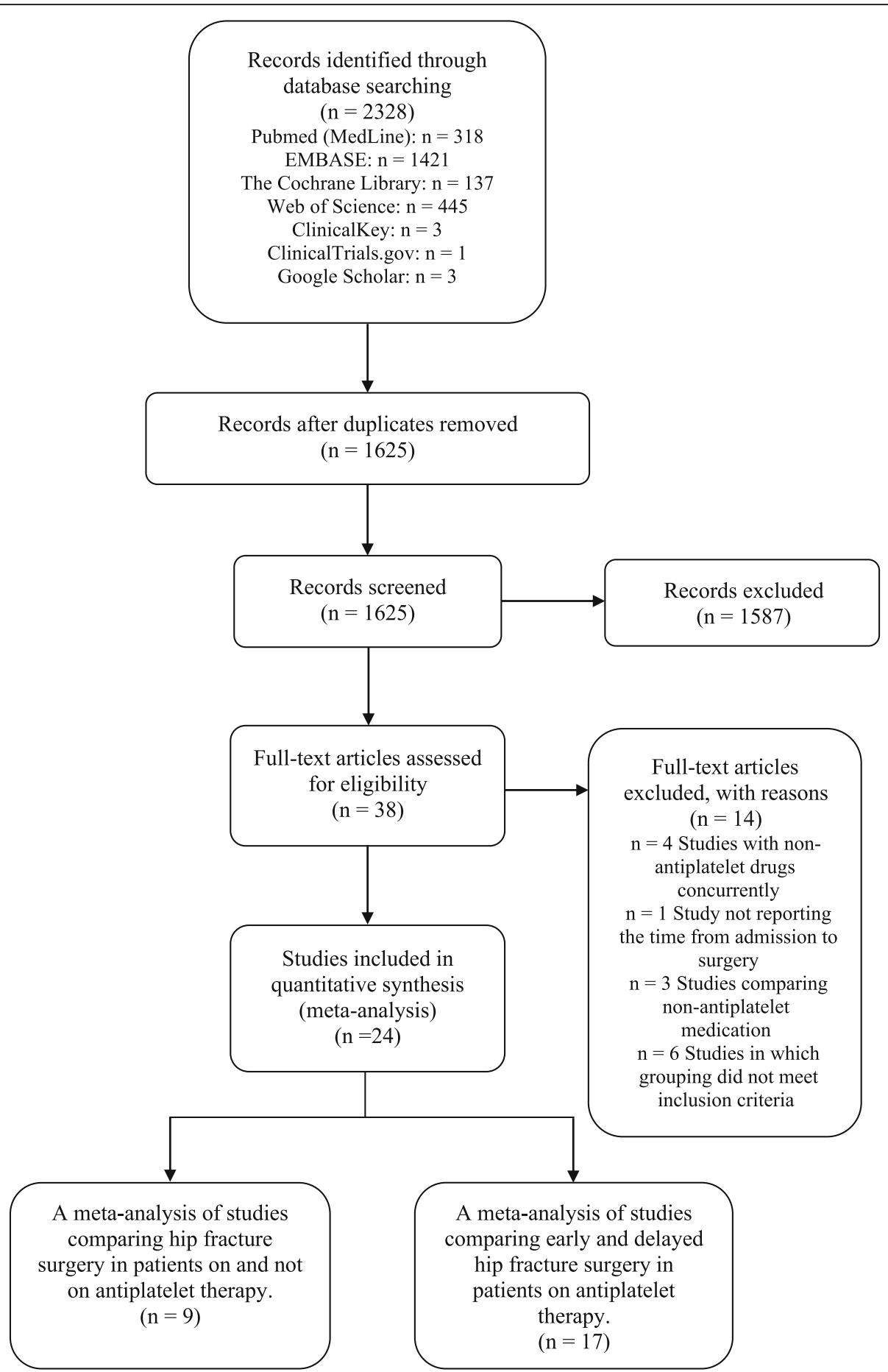

Fig. 1 The flowchart of the study selection procedure is presented

star system was adopted to provide a semi-quantitative evaluation of study quality. The NOS range is between zero and nine stars. Studies within 4 stars are considered to be of low quality, while those with 5 or more stars will be selected. The characteristics of all the included studies are presented in Table 2.

\section{Data collection and abstraction}

Two researchers independently extracted the data, including the title, lead author, publication year, country, study design, trial duration, number of participants, participant characteristics (mean age, gender, and fracture type), time to surgery, cohorts compared, surgical 
Table 1 Excluded studies and reasons for exclusion

\begin{tabular}{|c|c|}
\hline Excluded studies & Reasons for exclusion \\
\hline Manning et al. [10] & $\begin{array}{l}\text { This study did not report the time from admission } \\
\text { to theater. }\end{array}$ \\
\hline arty et al. [11] & $\begin{array}{l}\text { Antiplatelet intervention group was with delayed } \\
\text { surgery for more than } 5 \text { days. }\end{array}$ \\
\hline Dettoni et al. [12] & $\begin{array}{l}\text { Both antiplatelet intervention group and control } \\
\text { group were discontinued for more than } 5 \text { days } \\
\text { before surgery. }\end{array}$ \\
\hline $\begin{array}{l}\text { Leonidou et al. } \\
\text { [13] }\end{array}$ & $\begin{array}{l}\text { Antiplatelet intervention group was with delayed } \\
\text { surgery for more than } 5 \text { days. }\end{array}$ \\
\hline $\begin{array}{l}\text { Nwachuku et al. } \\
\text { [14] }\end{array}$ & $\begin{array}{l}\text { These groups were divided into early surgery group } \\
\text { or delayed surgery group based on the time from } \\
\text { admission to theater less than or more than } 48 \mathrm{~h} \text {. }\end{array}$ \\
\hline Lee et al. [15] & The study compared non-antiplatelet medication. \\
\hline Drescher et al. [16] & The study compared non-antiplatelet medication. \\
\hline $\begin{array}{l}\text { Kulachote et al. } \\
{[17]}\end{array}$ & $\begin{array}{l}\text { The intervention group was with non-antiplatelet } \\
\text { drugs concurrently. }\end{array}$ \\
\hline Akaoka et al. [18] & $\begin{array}{l}\text { n group was with non-antiplatelet } \\
\text { ntly. }\end{array}$ \\
\hline $\begin{array}{l}\text { Purushothaman } \\
\text { et al. [19] }\end{array}$ & $\begin{array}{l}\text { These groups were divided into early surgery group } \\
\text { or delayed surgery group based on the time from } \\
\text { admission to theater less than or more than } 48 \mathrm{~h} \text {. }\end{array}$ \\
\hline Hwang et al. [20] & $\begin{array}{l}\text { The intervention group was with non-antiplatelet } \\
\text { drugs concurrently. }\end{array}$ \\
\hline Zhang et al. [21] & $\begin{array}{l}\text { Antiplatelet intervention group was with delayed } \\
\text { surgery for more than } 5 \text { days. }\end{array}$ \\
\hline Lott et al. [22] & $\begin{array}{l}\text { The intervention group was with non-antiplatelet } \\
\text { drugs concurrently. }\end{array}$ \\
\hline Hoerlyck et al. [23] & The study compared non-antiplatelet medication. \\
\hline
\end{tabular}

treatment, concurrent antiplatelet use, and perioperative use of thromboprophylaxis. When the trials had more than 2 groups and allowed multiple comparisons, we only collected the relevant information and data reported in the original articles. The number of events was extracted for all dichotomous outcomes and means, and standard deviations (SDs) were extracted for all continuous outcomes. If these values were not available, they were indirectly derived from $p$ values or confidence intervals, if possible.

Outcomes were defined as a direct or indirect reflection of the surgical risk and prognosis of patients. All outcome data were extracted from included studies as far as possible. These included (1) in-hospital, 30-day, 3-month, and 1-year mortality; (2) blood transfusion exposures; (3) the average blood transfusion unit per patient; (4) decreases in hemoglobin; (5) length of hospital stay; (6) reoperation rate; and (7) postoperative complications including acute coronary syndrome, cerebrovascular events, deep vein thrombosis, pulmonary embolism, wound-related complications (infection and hematoma), and major bleeding (major bleeding was defined according to Eriksson et al. [49] as follows: (1) fatal bleeding, (2) excessive bleeding resulting in an intraoperative transfusion of four or more units of red blood cells, (3) bleeding involved any critical organ, and (4) bleeding that led to reoperation.

\section{Meta-analysis methodology}

Actually, the following two meta-analyses were performed on the identified studies: (1) studies comparing early surgery ( $<5$ days) in hip fracture patients with antiplatelet therapy versus those without antiplatelet therapy and (2) studies comparing early surgery ( $<5$ days) versus delayed surgery ( $>5$ days) in patients with hip fractures receiving antiplatelet therapy. To evaluate whether there is a difference due to drugs between the antiplatelet and non-antiplatelet groups, we specified subgroups based on the antiplatelet treatment (aspirin, clopidogrel, or the combination of aspirin and clopidogrel). If possible, data were used from patients only on one specified drug while not on other antiplatelet drugs.

We performed a meta-analysis to calculate the odds ratios (ORs) or weighted mean differences (WMDs) presented with $95 \%$ confidence intervals (CIs) using the Mantel-Haenszel statistical method. According to the Cochrane Handbook [50], trials with no events in either the intervention or control group were not included in the meta-analysis when ORs were calculated. The $I^{2}$ statistic was used to estimate the statistical heterogeneity between statistical data. A random-effects model was adopted when the heterogeneity was significant ( $p$ $<0.05$ ), and a fixed-effects model was used if heterogeneity was absent. Publication bias was evaluated using funnel plots. Sensitivity analysis was performed by excluding studies without controlling for confounding variables or studies with characteristics different from the others. All meta-analyses were conducted using Review Manager 5.3, and $p<0.05$ was regarded as statistically significant.

\section{Results}

Can early surgery be safely implemented on hip fracture patients who are treated with antiplatelet therapy?

A total of 17 studies were included to compare early surgery for hip fracture patients treated with antiplatelet therapy with those without antiplatelet therapy. As shown in Table 3, no significant differences in inhospital mortality, 30-day mortality, or 1-year mortality were observed. However, there was substantial heterogeneity $\left(p=0.007 ; I^{2}=68 \%\right)$ and an asymmetric funnel plot for 1-year mortality, which may be due to the trial by Kragh et al. [41]; thus, a random-effects model was used for this meta-analysis. Sensitivity analysis revealed that there was no evidence of heterogeneity in the 


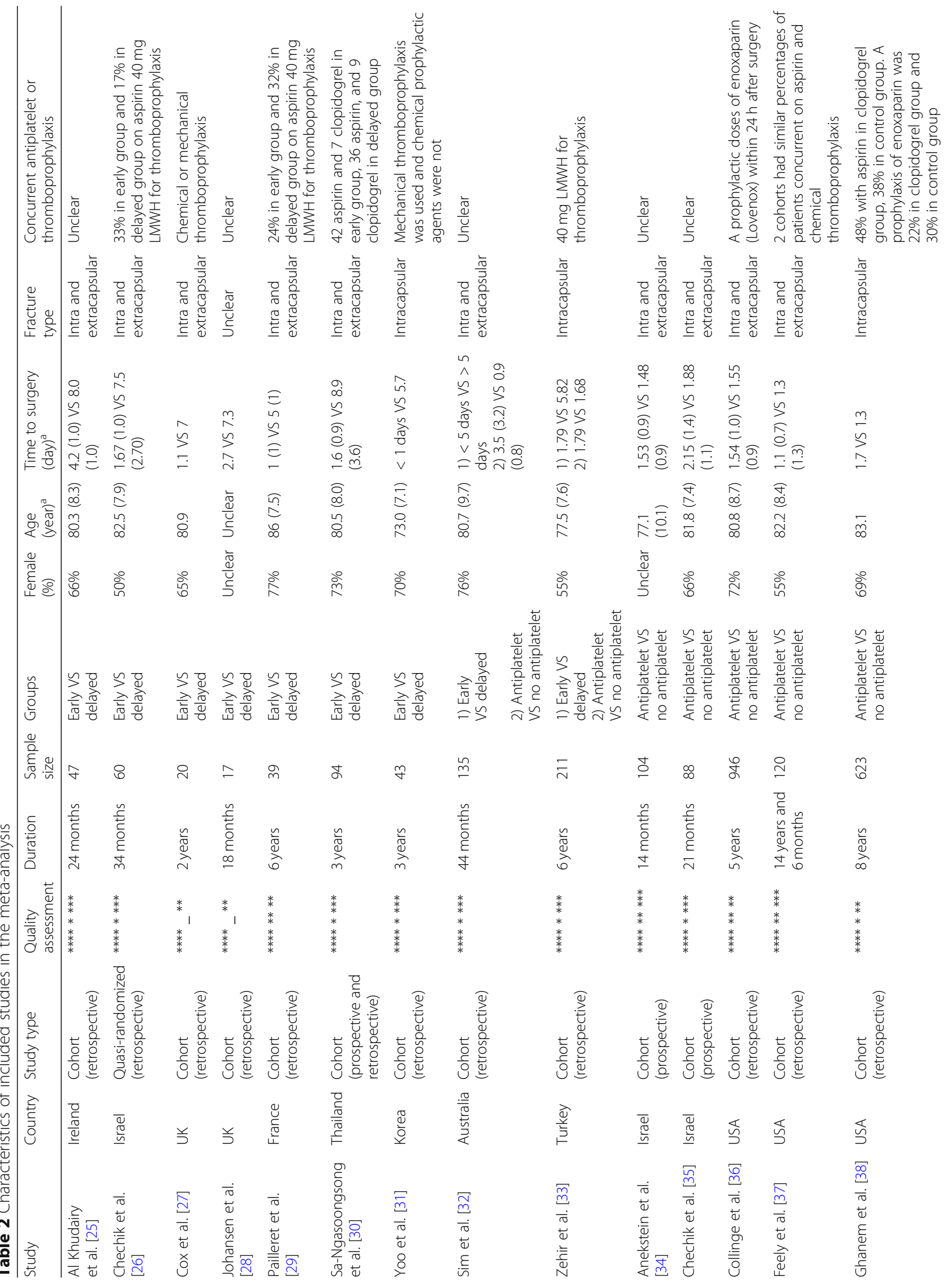




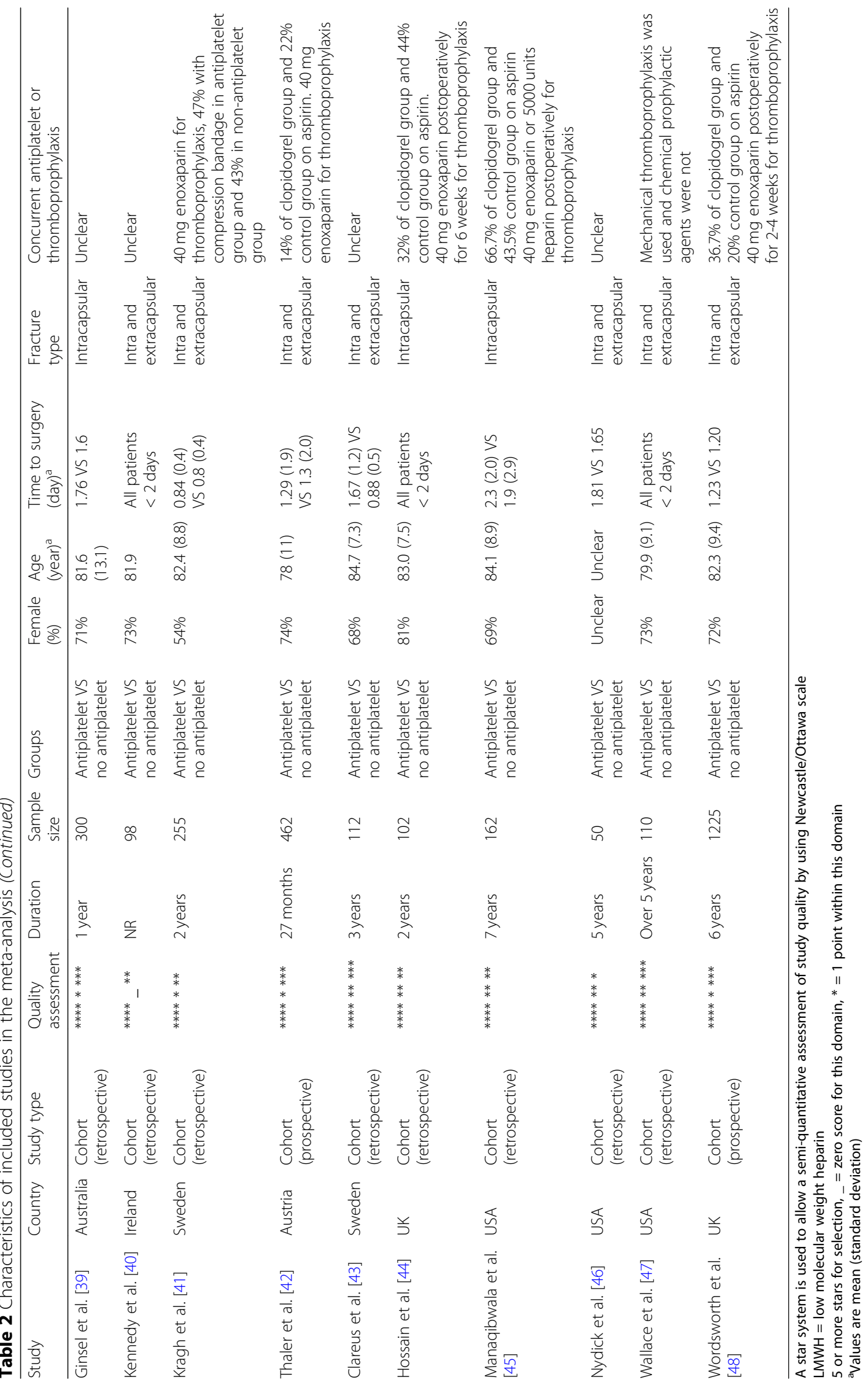


Table 3 Outcomes of meta-analysis in early surgery for hip fracture patients with or without antiplatelet therapy and subgroup analysis based on different drug regimens

\begin{tabular}{|c|c|c|c|c|c|c|c|c|}
\hline \multirow[t]{2}{*}{ Outcomes } & \multirow{2}{*}{$\begin{array}{l}\text { No. of } \\
\text { trials }\end{array}$} & \multicolumn{2}{|c|}{ No. of participants } & \multirow{2}{*}{$\begin{array}{l}\text { WMD or OR } \\
(95 \% \mathrm{Cl})\end{array}$} & \multirow{2}{*}{$\begin{array}{l}\text { Subtotal } \\
p \text { value }\end{array}$} & \multirow{2}{*}{$\begin{array}{l}\text { Subtotal Heterogenicity } \\
\left(I^{2}=\%\right)\end{array}$} & \multirow{2}{*}{$\begin{array}{l}p \text { value between } \\
\text { subgroup }\left(P^{2}=\%\right)\end{array}$} & \multirow{2}{*}{$\begin{array}{l}p \\
\text { value }\end{array}$} \\
\hline & & Antiplatelet & Control & & & & & \\
\hline \multicolumn{9}{|l|}{ In-hospital mortality } \\
\hline Aspirin & 3 & $11 / 456$ & $24 / 1128$ & $1.11(0.54-2.32)$ & 0.77 & 0 & \multirow[t]{3}{*}{0.81} & \multirow[t]{3}{*}{0.59} \\
\hline Clopidogrel & 4 & $2 / 106$ & $26 / 1242$ & $1.17(0.34-3.99)$ & 0.80 & 0 & & \\
\hline Clopidogrel and aspirin & 1 & $1 / 34$ & $8 / 619$ & $2.31(0.28-19.05)$ & 0.44 & Not applicable & & \\
\hline \multicolumn{9}{|l|}{ 30-day mortality } \\
\hline Aspirin & 2 & $25 / 371$ & $42 / 756$ & $1.22(0.72-2.07)$ & 0.47 & 89 & \multirow[t]{3}{*}{0.64} & \multirow[t]{3}{*}{0.56} \\
\hline Clopidogrel & 5 & 8/182 & $121 / 2070$ & $1.20(0.55-2.60)$ & 0.65 & 0 & & \\
\hline Clopidogrel and aspirin & 1 & $1 / 34$ & $39 / 619$ & $0.45(0.06-3.38)$ & 0.44 & Not applicable & & \\
\hline \multicolumn{9}{|l|}{ 1-year mortality } \\
\hline Aspirin & 2 & $85 / 371$ & $131 / 756$ & $1.91(0.56-6.54)$ & 0.30 & 90 & \multirow[t]{3}{*}{0.55} & \multirow[t]{3}{*}{0.43} \\
\hline Clopidogrel & 3 & $29 / 110$ & $488 / 1534$ & $0.90(0.49-1.64)$ & 0.72 & 41 & & \\
\hline Clopidogrel and aspirin & 1 & $7 / 34$ & $117 / 619$ & $1.11(0.47-2.62)$ & 0.81 & Not applicable & & \\
\hline \multicolumn{9}{|l|}{ Drop in hemoglobin } \\
\hline Aspirin & 4 & 450 & 879 & $0.12(-0.06-0.31)$ & 0.18 & 0 & \multirow[t]{3}{*}{0.88} & \multirow[t]{3}{*}{0.08} \\
\hline Clopidogrel & 6 & 201 & 1017 & $0.16(-0.10-0.42)$ & 0.22 & 0 & & \\
\hline Clopidogrel and aspirin & 1 & 34 & 619 & $0.00(-0.58-0.58)$ & 1.00 & Not applicable & & \\
\hline \multicolumn{9}{|c|}{ Number of patients receiving blood transfusion } \\
\hline Aspirin & 4 & $253 / 450$ & $465 / 879$ & $1.16(0.91-1.46)$ & 0.23 & 0 & \multirow[t]{3}{*}{0.39} & \multirow[t]{3}{*}{0.03} \\
\hline Clopidogrel & 10 & $118 / 361$ & $875 / 2965$ & $1.19(0.90-1.59)$ & 0.23 & 36 & & \\
\hline Clopidogrel and aspirin & 1 & $24 / 34$ & $337 / 619$ & $2.01(0.94-4.27)$ & 0.07 & Not applicable & & \\
\hline Mean number of units of & lood trar & sfused & & & & & & \\
\hline Aspirin & 5 & 530 & 1185 & $0.13(-0.13-0.40)$ & 0.32 & 49 & 0.23 & 0.07 \\
\hline Clopidogrel & 7 & 250 & 2487 & $0.15(-0.25-0.56)$ & 0.46 & 71 & & \\
\hline Clopidogrel and aspirin & 2 & 49 & 641 & $0.69(0.10-1.28)$ & 0.02 & 0 & & \\
\hline Length of hospital stay & & & & & & & & \\
\hline Aspirin & 2 & 380 & 808 & $-0.39(-0.83-0.06)$ & 0.09 & 0 & 0.03 & 0.76 \\
\hline Clopidogrel & 6 & 257 & 1203 & $0.58(-0.17-1.34)$ & 0.13 & 0 & & \\
\hline Clopidogrel and aspirin & 2 & 49 & 641 & $0.97(-0.40-2.34)$ & 0.17 & 0 & & \\
\hline Reoperation & & & & & & & & \\
\hline Aspirin & 2 & $3 / 223$ & $3 / 304$ & $1.35(0.28-6.61)$ & 0.71 & 0 & 0.93 & 0.29 \\
\hline Clopidogrel & 6 & $10 / 216$ & $33 / 1037$ & $1.47(0.70-3.09)$ & 0.31 & 0 & & \\
\hline Acute coronary syndrome & & & & & & & & \\
\hline Aspirin & 1 & $8 / 118$ & $5 / 137$ & $1.92(0.61-6.04)$ & 0.26 & Not applicable & 0.52 & 0.004 \\
\hline Clopidogrel & 6 & $14 / 240$ & $19 / 984$ & $2.27(1.07-4.81)$ & 0.03 & 0 & & \\
\hline Clopidogrel and aspirin & 1 & $3 / 15$ & $0 / 22$ & $12.60(0.60-264.14)$ & 0.10 & Not applicable & & \\
\hline Cerebrovascular events & & & & & & & & \\
\hline Aspirin & 2 & $2 / 140$ & $1 / 159$ & $1.64(0.27-9.79)$ & 0.59 & 39 & 0.76 & 0.53 \\
\hline Clopidogrel & 3 & $2 / 84$ & $4 / 249$ & $1.77(0.35-9.04)$ & 0.49 & 0 & & \\
\hline Clopidogrel and aspirin & 1 & $0 / 15$ & $1 / 22$ & $0.46(0.02-12.12)$ & 0.64 & Not applicable & & \\
\hline Deep venous thrombosis & & & & & & & & \\
\hline Aspirin & 3 & $9 / 476$ & $11 / 923$ & $1.50(0.58-3.84)$ & 0.40 & 61 & 0.94 & 0.30 \\
\hline Clopidogrel & 4 & $2 / 162$ & $14 / 1435$ & $1.60(0.45-5.74)$ & 0.47 & 0 & & \\
\hline
\end{tabular}


Table 3 Outcomes of meta-analysis in early surgery for hip fracture patients with or without antiplatelet therapy and subgroup analysis based on different drug regimens (Continued)

\begin{tabular}{|c|c|c|c|c|c|c|c|c|}
\hline \multirow[t]{2}{*}{ Outcomes } & \multirow{2}{*}{$\begin{array}{l}\text { No. of } \\
\text { trials }\end{array}$} & \multicolumn{2}{|c|}{ No. of participants } & \multirow{2}{*}{$\begin{array}{l}\text { WMD or OR } \\
(95 \% \mathrm{Cl})\end{array}$} & \multirow{2}{*}{$\begin{array}{l}\text { Subtotal } \\
p \text { value }\end{array}$} & \multirow{2}{*}{$\begin{array}{l}\text { Subtotal Heterogenicity } \\
\left(I^{2}=\%\right)\end{array}$} & \multirow{2}{*}{$\begin{array}{l}p \text { value between } \\
\text { subgroup }\left(I^{2}=\%\right)\end{array}$} & \multirow{2}{*}{$\begin{array}{l}p \\
\text { value }\end{array}$} \\
\hline & & Antiplatelet & Control & & & & & \\
\hline Clopidogrel and aspirin & 1 & $0 / 34$ & $9 / 619$ & $0.93(0.05-16.33)$ & 0.96 & Not applicable & & \\
\hline \multicolumn{9}{|l|}{ Pulmonary embolism } \\
\hline Aspirin & 2 & $2 / 358$ & $4 / 786$ & $1.06(0.22-5.14)$ & 0.95 & 0 & 0.79 & 0.54 \\
\hline Clopidogrel & 6 & $2 / 251$ & $14 / 1664$ & $1.37(0.44-4.23)$ & 0.59 & 0 & & \\
\hline Clopidogrel and aspirin & 1 & $0 / 34$ & $2 / 619$ & $3.58(0.17-76.02)$ & 0.41 & Not applicable & & \\
\hline \multicolumn{9}{|l|}{ Wound-related complications } \\
\hline Aspirin & 4 & $14 / 498$ & $25 / 945$ & $0.86(0.44-1.69)$ & 0.67 & 0 & 0.34 & 0.48 \\
\hline Clopidogrel & 8 & $14 / 287$ & $35 / 2398$ & $1.52(0.75-3.09)$ & 0.24 & 0 & & \\
\hline Clopidogrel and aspirin & 2 & $2 / 49$ & $10 / 641$ & $2.60(0.49-13.74)$ & 0.26 & 0 & & \\
\hline \multicolumn{9}{|l|}{ Major bleeding } \\
\hline Aspirin & 1 & $3 / 98$ & $10 / 342$ & $1.05(0.28-3.89)$ & 0.94 & Not applicable & 0.58 & 0.48 \\
\hline Clopidogrel & 3 & $5 / 91$ & $13 / 444$ & $1.75(0.52-5.91)$ & 0.37 & 0 & & \\
\hline
\end{tabular}

remaining studies $\left(p=0.45 ; I^{2}=0 \%\right)$, and it did not change the overall results when this outlier study was removed.

We found that antiplatelet therapy was significantly associated with an increase in the number of transfused patients $(\mathrm{OR}=1.21 ; 95 \% \mathrm{CI}, 1.01-1.44 ; p=0.03)$. No evidence of statistical heterogeneity or publication bias was detected. Although the analysis of the three subgroups showed no differences in the transfusion rate, we focused on the overall results rather than on a separate subgroup because a test for interaction yielded a $p$ value of 0.39 .

There were no significant differences in the decline in hemoglobin or mean number of units of blood transfused between the two groups despite the increase in the transfusion rate. Moderate statistical heterogeneity ( $p=0.002 ; I^{2}=61 \%$ ) was observed for the mean number of units for transfusion, and a random-effect model was applied. Subgroup analysis showed that the combination of aspirin and clopidogrel may result in an increase in the mean number of units for transfusion (WMD $=0.69 ; 95 \%$ CI, 0.10-1.28; $p=0.02$ ). Sensitivity analysis was performed by excluding Zehir et al. [33], which was the primary source of statistical heterogeneity. This may be because in this study, the preoperative hemoglobin levels of the antiplatelet group were significantly lower than that of the control group. Following removal of this study, a remarkable decrease in heterogeneity $\left(p=0.08 ; I^{2}=37 \%\right)$ was observed and the overall results remained unchanged.

There was also no significant difference in the length of hospital stay, reoperation, cerebrovascular events, deep vein thrombosis, pulmonary embolism, major bleeding, or other wound-related complications between the antiplatelet and non-antiplatelet groups, except for acute coronary syndrome $(\mathrm{OR}=2.41 ; 95 \% \mathrm{CI}, 1.32-4.42$; $p=0.004)$. Subgroup analysis suggested that the results did not change due to treatment with aspirin, clopidogrel, or a combination of aspirin and clopidogrel. None of them showed significant heterogeneity or publication bias.

\section{Which is better, early or delayed surgery on hip fracture patients with antiplatelet therapy?}

A total of 9 studies were included to compare early surgery ( $<5$ days) with delayed surgery ( $>5$ days) for hip fracture patients treated with antiplatelet therapy upon admission. There was a significant decrease in mortality $(\mathrm{OR}=0.43 ; 95 \% \mathrm{CI}, 0.23-0.79 ; p=0.006)$ for those treated with antiplatelet therapy with early surgery (Fig. 2). No evidence of statistical heterogeneity or publication bias was observed. Sensitivity analysis did not change the overall results. Subgroup analysis revealed that the point estimate regarding the association of delayed surgery and mortality at any time point was increased, but only 3-month mortality reached statistical significance.

Early surgery was significantly associated with increased hemoglobin loss in hip fracture patients who received antiplatelet drugs (WMD $=0.75 ; 95 \% \mathrm{CI}, 0.50$ $1.00 ; p<0.001$ ) (Fig. 3). However, there were no significant differences in the number of blood transfusions (Fig. 4) or mean number of units for transfusion (Fig. $5)$. There was a remarkable statistical heterogeneity ( $p$ $=0.01 ; I^{2}=72 \%$ ) and possible publication bias for the mean number of units for transfusion. Sensitivity 


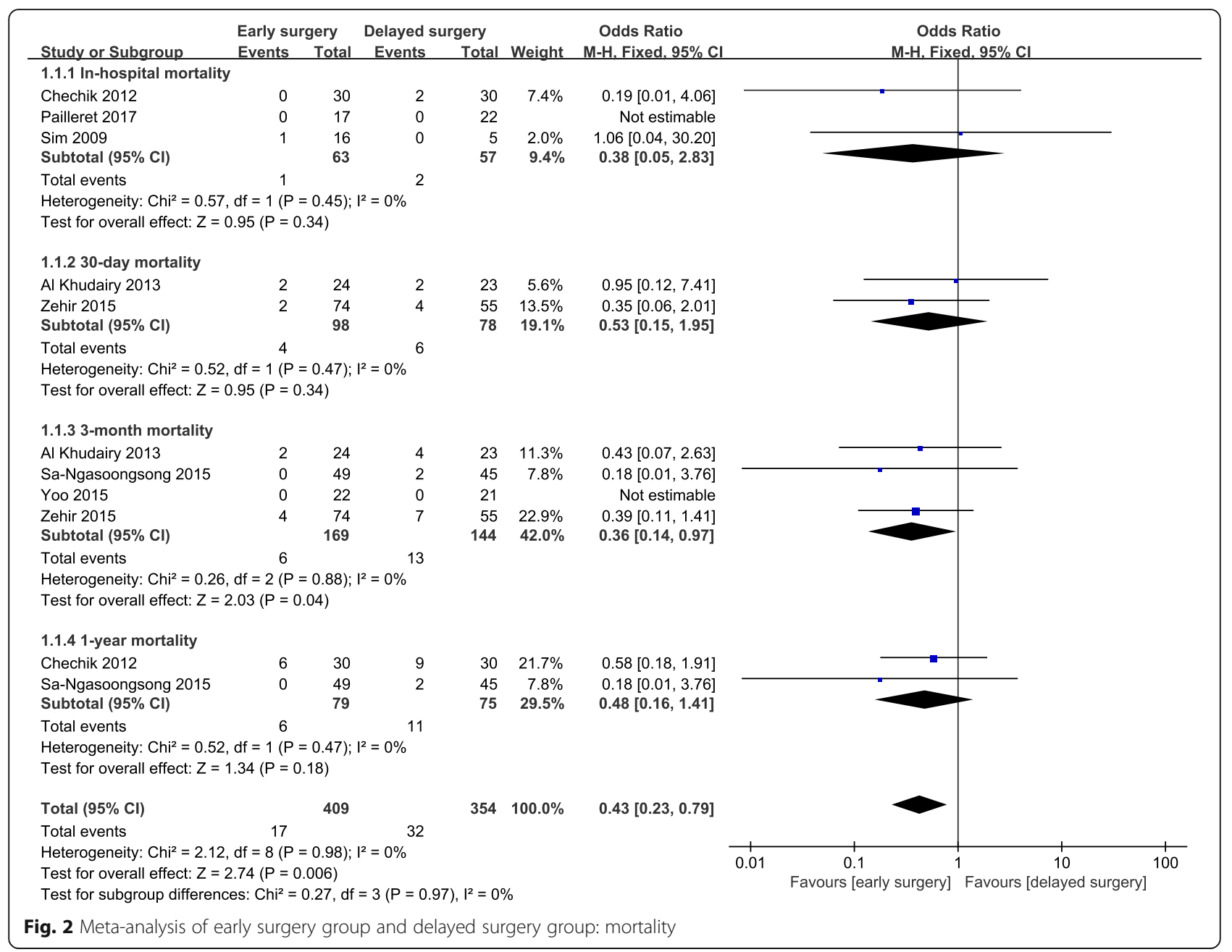

analysis was performed by separately excluding Zehir et al. [33], and the results remained unchanged.

The length of hospital stay in the early surgery group was significantly shortened (WMD $=-6.05 ; 95 \% \mathrm{CI}$, 7.06-5.04; $p<0.001$ ) (Fig. 6). Nevertheless, there were no significant differences for acute coronary syndrome, cerebrovascular events, deep vein thrombosis, pulmonary embolism, major bleeding, or other wound-related complications (Fig. 7). Moreover, no heterogeneity was observed, and the results were not altered by separately excluding subgroups after sensitivity analysis.

\section{Discussion}

Hip fracture patients tend to be older, with a high mortality rate, and their quality of life is seriously affected [51]. As the global elderly population is gradually increasing, the number of elderly patients with hip fractures and the socioeconomic burden are also

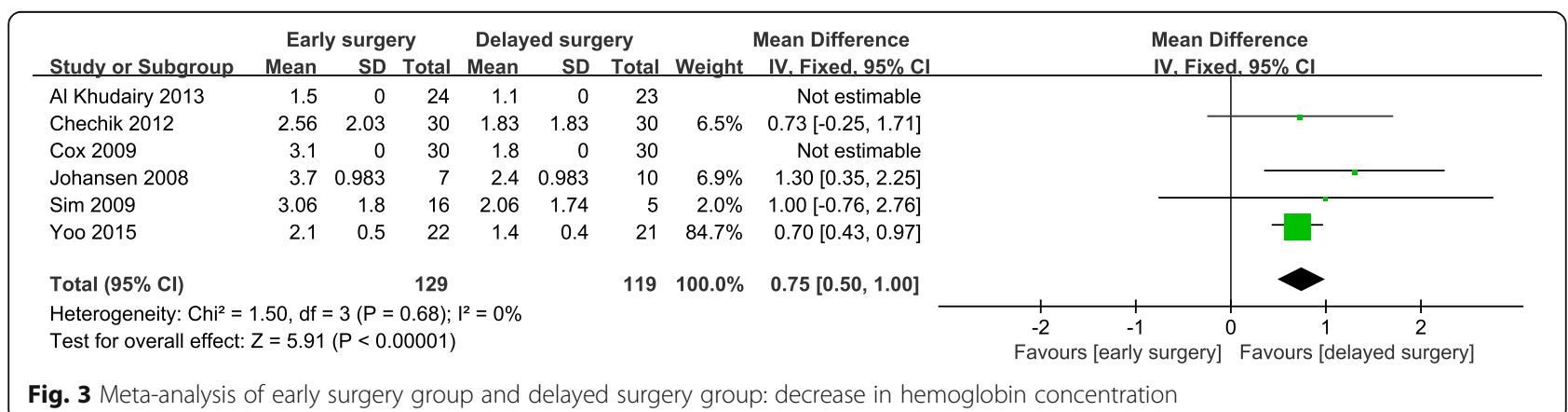




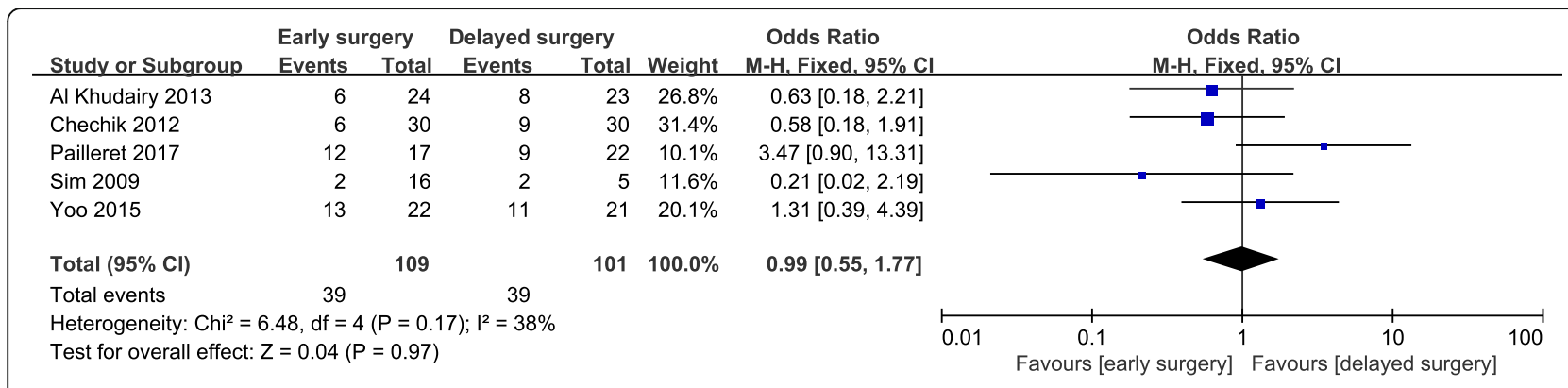

Fig. 4 Meta-analysis of early surgery group and delayed surgery group: transfusion exposures

increasing year by year $[52,53]$. Most of them usually suffer from cardio-cerebrovascular disease and need antiplatelet therapy. Some believe that it is necessary to withhold antiplatelet therapy to promote platelet function recovery and reduce the risk of perioperative bleeding. Others believe that surgery should be performed as soon as possible without stopping medication. Previous literature has found that there is an absence of a consensus or policies for the treatment of patients who sustain hip fractures while on antiplatelet therapy. A telephone questionnaire data analysis about current practical measures among 110 orthopedics in the UK showed that $56.4 \%$ of orthopedics did not have a standard of clopidogrel withdrawal, and the remaining $43.6 \%$ stopped clopidogrel before surgery. Among them, 20.9\% of the surgeries were delayed by more than 5 days, and $12.7 \%$ were delayed by $7-10$ days [54].

Although Soo et al. [55] and Doleman et al. [56] tried to identify how to manage these cases, the total number of studies included in these reviews were low, and these studies may result in type II errors and were either limited to one specific antiplatelet drug or confused the presence or absence of antiplatelet drugs with early or delayed surgery. Thus, we performed a more systematic and specific search and analysis to address the issues highlighted from previous research. The important finding of our study is that early surgery for hip fracture patients taking antiplatelet drugs might promote a higher risk of bleeding and more blood transfusion requirements compared to those without antiplatelet therapy. Nevertheless, there were no significant differences in prognosis. Instead, delayed intervention will lead to higher mortality and a longer hospital stay.

There were several limitations to our study. One of the limitations was that the methodological quality of the studies included was not optimal. Only observational studies were included in our analysis, which means that only the inference of association is possible rather than causality; there may be potential confounding variables that bias the outcomes. For instance, there were three main types of hip fracture surgery in included studies: hip repair using internal fixation, partial hip replacement surgery, and total hip replacement surgery. Different surgical methods will affect the outcomes, but most of the included studies did not distinguish and explain so that we were unable to exclude this confounding factor. As expected, the intervention groups in most studies [37, 38, 40, $41,44,45,47]$ showed a significant increase in the number of cardiovascular or cerebrovascular comorbidities; however, surprisingly, only three of them showed a significant difference in the ASA grade [38, $41,45]$. Moreover, the preoperative hemoglobin values of the intervention group in five studies [30, 33, 45,

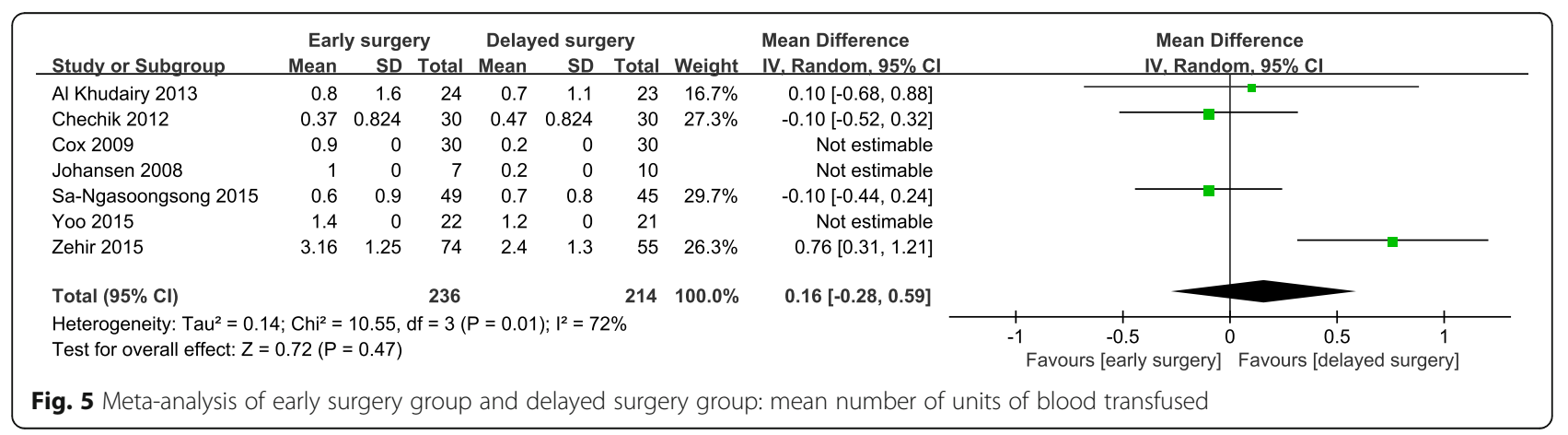




\begin{tabular}{|c|c|c|c|c|c|c|c|c|c|c|}
\hline \multirow[b]{2}{*}{ Study or Subgroup } & \multicolumn{3}{|c|}{ Early surgery } & \multicolumn{3}{|c|}{ Delayed surgery } & & \multirow{2}{*}{$\begin{array}{l}\text { Mean Difference } \\
\text { IV. Fixed, 95\% Cl }\end{array}$} & \multirow{2}{*}{\multicolumn{2}{|c|}{$\begin{array}{l}\text { Mean Difference } \\
\text { IV. Fixed. } 95 \% \mathrm{Cl}\end{array}$}} \\
\hline & Mean & SD & Total & Mean & SD & Total & Weight & & & \\
\hline Al Khudairy 2013 & 21.1 & 11.9 & 24 & 28.7 & 16.4 & 23 & $1.5 \%$ & $-7.60[-15.82,0.62]$ & & \\
\hline Chechik 2012 & 11.08 & 4.79 & 30 & 17.71 & 7.21 & 30 & $10.7 \%$ & $-6.63[-9.73,-3.53]$ & 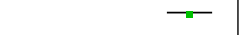 & \\
\hline Cox 2009 & 25 & 0 & 30 & 30 & 0 & 30 & & Not estimable & & \\
\hline Pailleret 2017 & 11 & 3 & 17 & 15 & 4 & 22 & $21.2 \%$ & $-4.00[-6.20,-1.80]$ & -1 & \\
\hline Sa-Ngasoongsong 2015 & 7 & 3 & 49 & 14 & 9 & 45 & $13.4 \%$ & $-7.00[-9.76,-4.24]$ & $\pi$ & \\
\hline Sim 2009 & 18.95 & 15.82 & 16 & 36.6 & 18.3 & 5 & $0.3 \%$ & $-17.65[-35.47,0.17]$ & & \\
\hline Zehir 2015 & 8.13 & 3.46 & 74 & 14.53 & 4.33 & 55 & $52.9 \%$ & $-6.40[-7.79,-5.01]$ & 들 & \\
\hline Total $(95 \% \mathrm{Cl})$ & & & 240 & & & 210 & $100.0 \%$ & $-6.05[-7.06,-5.04]$ & $\bullet$ & \\
\hline $\begin{array}{l}\text { Heterogeneity: } \mathrm{Chi}^{2}=5.9 \\
\text { Test for overall effect: } Z=\end{array}$ & $\begin{array}{l}d f=5( \\
11.73(P\end{array}$ & $\begin{array}{l}P=0.3 \\
<0.00\end{array}$ & 1); $1^{2}=$ & & & & & & $\begin{array}{ccc}-20 & -10 & 0 \\
\text { Favours [early surgery] }\end{array}$ & $\begin{array}{ccc}0 & 10 & 20 \\
& \text { Favours [delayed surgery] }\end{array}$ \\
\hline
\end{tabular}

46] were significantly lower than those of the control group, which may potentially influence blood transfusions, meaning that the intervention groups required more units of blood. This may be why Zehir et al. [33] was the main source of heterogeneity in the outcomes for the mean number of units for transfusion. A further limitation was that publication bias existed in some studies as shown in the funnel plots; this might be because the number of included trials was less than 10. Finally, although we performed subgroup analysis based on the types of antiplatelet drugs and data were used from patients on one specific drug and not on the others simultaneously as much as possible, most of the trials included patients concurrently treated with aspirin in the clopidogrel subgroup, and this may affect the final results.

Regarding whether early surgery is safe for hip fracture patients taking antiplatelet drugs, the number of patients transfused in the antiplatelet group increased statistically, which was consistent with that in cardiac surgery [57, 58]. However, we found no convincing evidence of an increase in the average blood transfusion demands, except for in the medicine-united group. This suggested that there might indeed be an increased risk of bleeding in intraoperative blood loss or hidden blood loss, especially when antiplatelet drugs are used in combination [35]. However, because of the concerns of antiplatelets from anaesthesiologists and physicians, the patients taking antiplatelet drugs are more likely to have a lower threshold to receive transfusions. No differences in mortality, duration of hospital stay, reoperation rate, or related complications, except acute coronary syndrome, were detected between the two groups. The presence of more vascular comorbidities in the antiplatelet group of most studies may be responsible for the significant increase in acute coronary syndrome.

Regarding whether early or delayed surgery is better for patients with hip fractures on antiplatelet therapy, early surgery was associated with a greater decrease in hemoglobin; however, there were no differences in the transfusion rate or mean number of units for transfusion. This also supports the fact that patients taking antiplatelet drugs are more likely to be transfused owing to potential performance bias. Multiple studies have shown that delays in surgery for more than 2 days for hip fracture patients are closely related to an increased risk of complications due to long-term bedridden and delayed mobilization [59, 60]. Early surgical intervention can significantly reduce postoperative mortality and morbidity, promote a shorter hospital stay, and prompt patients to return to preinjury ambulation status [61-65]. However, early surgery for patients on antiplatelet may cause hemorrhagic accidents, as platelet function has not fully recovered [66]. In our study, delayed surgery increased the risk of mortality, and subgroup analysis showed that the point estimate regarding mortality at any time point was increased, especially mortality at 30 days and 3 months, which showed significant differences. Furthermore, hip fractures are more likely to prolong the length of hospital stay than any other musculoskeletal injuries, accounting for more than two-thirds of all hospital stays caused by fractures [67]. Early surgery can effectively shorten the length of hospital stay and reduce social and economic burdens. Unlike previous research studies, our study suggests that there are no differences in the incidence of postoperative complications between early and delayed surgery. Previous studies have demonstrated that sudden withdrawal will lead to conversion to a prothrombotic and proinflammatory condition, which may complicate surgery and lead to adverse clinical events, such as recurrence and death by myocardial infarction, which has already been stabilized by drugs or stents [68]. However, in the meta-analysis reported here, subgroup analysis showed that a surgical delay did not have a higher postoperative incidence of cardiocerebrovascular events or thromboembolic events, and early surgery did not result in a higher incidence of severe bleeding. 


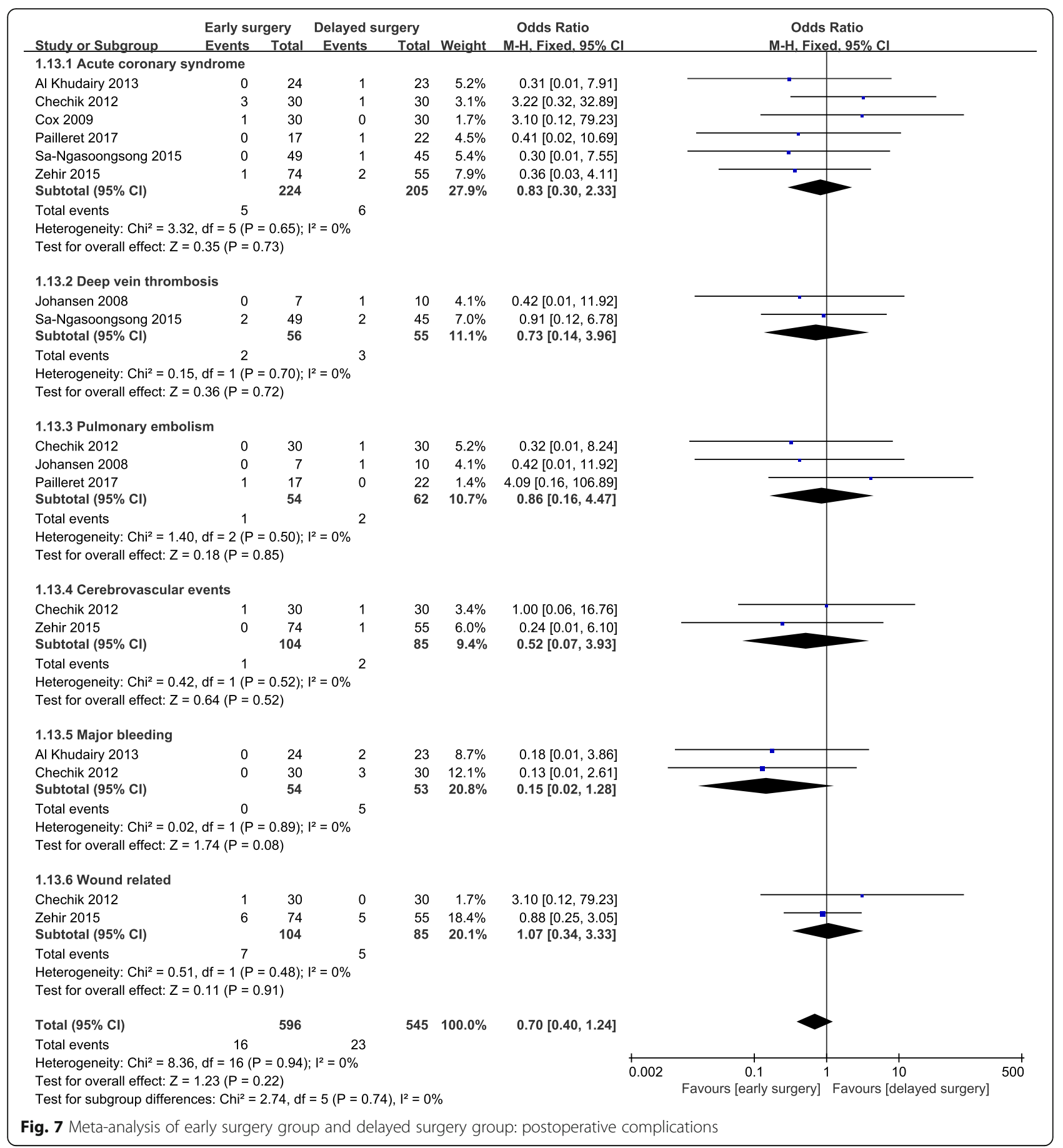

\section{Conclusion}

In conclusion, our analysis of 24 trials including a total of 5423 patients suggests that early surgery can be safely performed on hip fracture patients receiving antiplatelet drugs upon admission. Current evidence shows that although early surgery carries a high risk of bleeding, it does not lead to substantial blood transfusion demands or hemorrhagic events. Furthermore, compared with delayed surgery, early surgical intervention is associated with a significant decrease in mortality $(p=0.006)$ and length of hospital stay $(p<0.001)$. Based on the available evidence, it is unnecessary to delay surgery to restore platelet function when patients with hip fractures receive antiplatelet therapy. Early surgery can significantly reduce mortality and hospital stay, which is conducive to patient recovery. Further large-scale, multi-centered, well-motivated and well-designed randomized trials are required to confirm these findings and develop clearer guidelines for the treatment of these patients. 


\section{Supplementary information}

Supplementary information accompanies this paper at https://doi.org/10. 1186/s13018-020-01624-7.

\section{Additional file 1}

\section{Abbreviations}

PRISMA: Preferred Reporting Items for Systematic Review and Meta-Analysis statement; NOS: Newcastle/Ottawa scale; SDs: Standard deviations; ORs: Odds ratios; WMDs: Weighted mean differences; Cls: Confidence intervals

\section{Acknowledgements}

We thank the authors of the included studies for their help.

\section{Authors' contributions}

JDN and ZYY contributed to the conception and design of the study. ZYY performed the statistical analysis and drafted the manuscript. ZL and LTK contributed to the literature search and study selection. LTK and YQG contributed to the quality assessment. YQG and SBT contributed to the data extraction. SBT contributed to the revisions of the manuscript. All authors read and approved the final manuscript.

\section{Funding}

None.

\section{Availability of data and materials}

All data generated or analyzed during this study are included in published articles.

\section{Ethics approval and consent to participate}

This article does not contain any studies with human participants or animals performed by any of the authors.

\section{Consent for publication}

Not applicable.

\section{Competing interests}

The authors declare that they have no competing interests.

\section{Received: 5 February 2020 Accepted: 4 March 2020}

Published online: 12 March 2020

\section{References}

1. Morris AH, Zuckerman JD. National consensus conference on improving the continuum of care for patients with hip fracture. J Bone Joint Surg Am. 2002:84-a(4):670-4

2. Koval KJ, Zuckerman JD. Hip fractures: I. Overview and evaluation and treatment of femoral-neck fractures. J Am Acad Orthop Surg. 1994:2(3):141-9.

3. Holt G, Smith R, Duncan K, Finlayson DF, Gregori A. Early mortality after surgical fixation of hip fractures in the elderly: an analysis of data from the Scottish hip fracture audit. J Bone Joint Surg Br. 2008;90(10):1357-63.

4. Holt G, Smith R, Duncan K, Hutchison JD, Gregori A. Epidemiology and outcome after hip fracture in the under 65 s-evidence from the Scottish hip fracture audit. Injury. 2008;39(10):1175-81.

5. Baggish AL, Sabatine MS. Clopidogrel use in coronary artery disease. Expert Rev Cardiovasc Ther. 2006:4(1):7-15

6. Pickard AS, Becker RC, Schumock GT, Frye CB. Clopidogrel-associated bleeding and related complications in patients undergoing coronary artery bypass grafting. Pharmacotherapy. 2008;28(3):376-92.

7. Horlocker TT, Wedel DJ, Benzon H, et al. Regional anesthesia in the anticoagulated patient: defining the risks (the second ASRA Consensus Conference on Neuraxial Anesthesia and Anticoagulation). Reg Anesth Pain Med. 2003;28(3):172-97.

8. Lavelle WF, Demers Lavelle EA, UhI R. Operative delay for orthopedic patients on clopidogrel (plavix): a complete lack of consensus. J Trauma. 2008:64(4):996-1000.

9. Moher D, Shamseer $L$, Clarke $M$, et al. Preferred reporting items for systematic review and meta-analysis protocols (PRISMA-P) 2015 statement. Syst Rev. 2015;4(1):1.
10. Manning BJ, O'Brien N, Aravindan S, Cahill RA, McGreal G, Redmond HP. The effect of aspirin on blood loss and transfusion requirements in patients with femoral neck fractures. Injury-Int J Care Injured. 2004;35(2):121-4.

11. Harty JA, McKenna P, Moloney D, D'Souza L, Masterson E. Anti-platelet agents and surgical delay in elderly patients with hip fractures. J Orthop Surg (Hong Kong). 2007:15(3):270-2.

12. Dettoni F, Castoldi F, Giai Via A, Parisi S, Bonasia DE, Rossi R. Influence of timing and oral anticoagulant/antiplatelet therapy on outcomes of patients affected by hip fractures. Eur J Trauma Emerg Surg. 2011;37(5):511-8.

13. Leonidou A, Cam NB, Chambers IR. Femoral neck fractures in patients on clopidogrel. The effect of delaying surgery and the introduction of the new SIGN guidelines. Surgeon-J Royal Colleges Surgeons Edinburgh Ireland. 2011:9(6):318-21.

14. Nwachuku IC, Jones M, Clough TM. Clopidogrel: is a surgical delay necessary in fractured neck of femur? Ann R Coll Surg Engl. 2011:93(4):310-3.

15. Lee A, Larson R, Morrison D, Chiang W. Drescher F. Aspirin versus anticoagulation for the prevention of venous thromboembolism in orthopedic patients after lower extremity reconstructive surgery - a systematic review. Chest. 2012;142(4). https://doi.org/10.1378/chest.1374115.

16. Drescher FS, Sirovich BE, Lee A, Morrison DH, Chiang WH, Larson RJ. Aspirin versus anticoagulation for prevention of venous thromboembolism major lower extremity orthopedic surgery: a systematic review and meta-analysis. J Hosp Med. 2014;9(9):579-85.

17. Kulachote N, Sa-Ngasoongsong P, Sirisreetreerux N, et al. The impacts of early hip surgery in high-risk elderly taking antithrombotic agents and afflicted with intertrochanteric fracture. J Med Assoc Thailand. 2015;98(9, Suppl. 8):S76-81.

18. Akaoka Y, Yamazaki $\mathrm{H}$, Kodaira $\mathrm{H}$, Kato H. Risk factors for the effect of anticoagulant and antiplatelet agents on perioperative blood loss following proximal femoral fractures. Medicine. 2016;95(27):e4120.

19. Purushothaman B, Webb M, Weusten A, Bonczek S, Ramaskandhan J, Nanu A. Decision making on timing of surgery for hip fracture patients on clopidogrel. Ann R Coll Surg England. 2016;98(2):91-5.

20. Hwang J-Y, Oh S, Kim C-S, Chang J-E, Min S-W. Perioperative complications following preoperative cessation of antithrombotic agents for total knee arthroplasty: a retrospective study. Medicine. 2016;95(48):e5487.

21. Zhang JZ, Gao J, Han L, et al. Safety of early minimally invasive surgical treatment of elderly patients with hip fractures without ceasing anti-platelet drugs. Academic J Second Military Med University. 2017;38(4):447-51.

22. Lott A, Haglin J, Belayneh R, Konda SR, Leucht P, Egol KA. Does use of oral anticoagulants at the time of admission affect outcomes following hip fracture. Geriatr Orthop Surg Rehabil. 2018;9:2151459318764151.

23. Hoerlyck C, Ong T, Gregersen M, et al. Do anticoagulants affect outcomes of hip fracture surgery? A cross-sectional analysis. Arch Orthop Trauma Surg. 2019;140(2):171-6.

24. Stang A. Critical evaluation of the Newcastle-Ottawa scale for the assessment of the quality of nonrandomized studies in meta-analyses. Eur J Epidemiol. 2010;25(9):603-5.

25. Al Khudairy A, Al-Hadeedi O, Sayana MK, Galvin R, Quinlan JF. Withholding clopidogrel for 3 to 6 versus 7 days or more before surgery in hip fracture patients. J Orthop Surg. 2013;21(2):146-50

26. Chechik O, Amar E, Khashan M, Kadar A, Rosenblatt Y, Maman E. In support of early surgery for hip fractures sustained by elderly patients taking clopidogrel: a retrospective study. Drugs Aging. 2012;29(1):63-8.

27. Cox G, Talbot C, Topp K, Templeton P. Clopidogrel and proximal femoral fractures: does timing of surgery affect blood loss and length of admission? A preliminary study prior to multicenter trial. Eur J Trauma Emerg Surg. 2009;35(3):291-5.

28. Johansen A, White J, Turk A. Clopidogrel therapy-implications for hip fracture surgery. Injury-Int J Care Injured. 2008;39(10):1188-90.

29. Pailleret C, Ait Hamou Z, Rosencher N, et al. A retrospective comparison between delayed and early hip fracture surgery in patients taking clopidogrel: same total bleeding but different timing of blood transfusion. Int Orthop. 2017;41(9):1839-44

30. Sa-Ngasoongsong P, Kulachote N, Sirisreetreerux N, et al. Effect of early surgery in high surgical risk geriatric patients with femoral neck fracture and taking antiplatelet agents. World J Orthop. 2015;6(11):970-6.

31. Yoo HS, Cho YH, Byun YS, Kim MG. Is taking an antiplatelet agent a contraindication for early surgery in displaced femur neck fracture? Hip Pelvis. 2015;27(3):173-8.

32. Sim W, Gonski PN. The management of patients with hip fractures who are taking clopidogrel. Australas J Ageing. 2009;28(4):194-7. 
33. Zehir S, Zehir R, Sarak T. Early surgery is feasible in patients with hip fractures who are on clopidogrel therapy. Acta Orthop Traumatol Turc 2015;49(3):249-54.

34. Anekstein $Y$, Tamir $E$, Halperin N, Mirovsky Y. Aspirin therapy and bleeding during proximal femoral fracture surgery. Clin Orthop Relat Res. 2004;418: 205-8.

35. Chechik O, Thein R, Fichman G, Haim A, Tov TB, Steinberg EL. The effect of clopidogrel and aspirin on blood loss in hip fracture surgery. Injury. 2011; 42(11):1277-82.

36. Collinge CA, Kelly KC, Little B, Weaver T, Schuster RD. The effects of clopidogrel (Plavix) and other oral anticoagulants on early hip fracture surgery. J Orthop Trauma. 2012;26(10):568-73.

37. Feely MA, Mabry TM, Lohse CM, Sems SA, Mauck KF. Safety of clopidogrel in hip fracture surgery. Mayo Clin Proc. 2013;88(2):149-56.

38. Ghanem ES, Richard RD, Wingert NCH, Gotoff JR, Graham JH, Bowen TR. Preoperative use of clopidogrel does not affect outcomes for femoral neck fractures treated with hemiarthroplasty. J Arthroplasty. 2017;32(7):2171-5.

39. Ginsel BL, Taher A, Whitehouse SL, Bell JJ, Pulle CR, Crawford RW. Effects of anticoagulants on outcome of femoral neck fracture surgery. J Orthop Surg. 2015;23(1):29-32.

40. Kennedy MT, Roche S, Fleming SM, Lenehan B, Curtin W. The association between aspirin and blood loss in hip fracture patients. Acta Orthop Belg. 2006;72(1):29-33.

41. Kragh AM, Walden M, Apelqvist A, Wagner P, Atroshi I. Bleeding and firstyear mortality following hip fracture surgery and preoperative use of lowdose acetylsalicylic acid: an observational cohort study. BMC Musculoskelet Disord. 2011;12:254.

42. Thaler HW, Frisee F, Korninger C. Platelet aggregation inhibitors, platelet function testing, and blood loss in hip fracture surgery. J Trauma. 2010;69(5): 1217-20.

43. Clareus A, Fredriksson I, Wallen H, Gordon M, Stark A, Skoldenberg O. Variability of platelet aggregation in patients with clopidogrel treatment and hip fracture: a retrospective case-control study on 112 patients. World J Orthop. 2015:6(5):439-45.

44. Hossain FS, Rambani R, Ribee H, Koch L. Is discontinuation of clopidogrel necessary for intracapsular hip fracture surgery? Analysis of 102 hemiarthroplasties. J Orthop Traumatol. 2013;14(3):171-7.

45. Manaqibwala MI, Butler KA, Sagebien CA. Complications of hip fracture surgery on patients receiving clopidogrel therapy. Arch Orthop Trauma Surg. 2014;134(6):747-53.

46. Nydick JA, Farrell ED, Marcantonio AJ, Hume EL, Marburger R, Ostrum RF. The use of clopidogrel (Plavix) in patients undergoing nonelective orthopaedic surgery. J Orthop Trauma. 2010;24(6):383-6.

47. Wallace HC, Probe RA, Chaput CD, Patel KV. Operative treatment of hip fractures in patients on clopidogrel: a case-control study. lowa Orthop J. 2012;32:95-9.

48. Wordsworth DR, Halsey T, Griffiths R, Parker MJ. Clopidogrel has no effect on mortality from hip fracture. Injury. 2013;44(6):743-6.

49. Eriksson BI, Bauer KA, Lassen MR, Turpie AG. Fondaparinux compared with enoxaparin for the prevention of venous thromboembolism after hipfracture surgery. N Engl J Med. 2001;345(18):1298-304.

50. Higgins J, Green S. Cochrane handbook for systematic reviews of interventions version 5.1.0 [updated March 2011]. 2011; http://handbook. cochrane.org.

51. Maheshwari R, Acharya M, Monda M, Pandey R. Factors influencing mortality in patients on antiplatelet agents presenting with proxima femoral fractures. J Orthop Surg (Hong Kong). 2011;19(3):314-6.

52. Johnell $\mathrm{O}$, Kanis JA. An estimate of the worldwide prevalence, mortality and disability associated with hip fracture. Osteoporos Int. 2004;15(11):897-902.

53. White SM, Griffiths R. Projected incidence of proximal femoral fracture in England: a report from the NHS Hip Fracture Anaesthesia Network (HIPFAN). Injury. 2011;42(11):1230-3.

54. Palan J, Odutola A, White SP. Is clopidogrel stopped prior to hip fracture surgery--a survey of current practice in the United Kingdom. Injury. 2007; 38(11):1279-85.

55. Soo CG, Della Torre PK, Yolland TJ, Shatwell MA. Clopidogrel and hip fractures, is it safe? A systematic review and meta-analysis. BMC Musculoskelet Disord. 2016;17:136.

56. Doleman B, Moppett IK. Is early hip fracture surgery safe for patients on clopidogrel? Systematic review, meta-analysis and meta-regression. Injury. 2015;46(6):954-62
57. Herman CR, Buth KJ, Kent BA, Hirsch GM. Clopidogrel increases blood transfusion and hemorrhagic complications in patients undergoing cardiac surgery. Ann Thorac Surg. 2010;89(2):397-402.

58. Purkayastha S, Athanasiou T, Malinovski V, et al. Does clopidogrel affect outcome after coronary artery bypass grafting? A meta-analysis. Heart. 2006; 92(4):531-2.

59. Lefaivre KA, Macadam SA, Davidson DJ, Gandhi R, Chan H, Broekhuyse HM. Length of stay, mortality, morbidity and delay to surgery in hip fractures. Bone Joint Surg Br. 2009;91(7):922-7.

60. Shiga T, Wajima Z, Ohe Y. Is operative delay associated with increased mortality of hip fracture patients? Systematic review, meta-analysis, and meta-regression. Can J Anaesth. 2008;55(3):146-54

61. Siegmeth AW, Gurusamy K, Parker MJ. Delay to surgery prolongs hospital stay in patients with fractures of the proximal femur. J Bone Joint Surg Br. 2005;87(8):1123-6.

62. McGuire KJ, Bernstein J, Polsky D, Silber JH. The 2004 Marshall Urist award: delays until surgery after hip fracture increases mortality. Clin Orthop Relat Res. 2004;428:294-301. https://doi.org/10.1097/01.blo.0000146743.28925.1c.

63. Al-Ani AN, Samuelsson B, Tidermark J, et al. Early operation on patients with a hip fracture improved the ability to return to independent living. A prospective study of 850 patients. J Bone Joint Surg Am. 2008;90(7):143642.

64. Simunovic N, Devereaux PJ, Sprague S, et al. Effect of early surgery after hip fracture on mortality and complications: systematic review and metaanalysis. Cmaj. 2010;182(15):1609-16.

65. Khan SK, Kalra S, Khanna A, Thiruvengada MM, Parker MJ. Timing of surgery for hip fractures: a systematic review of 52 published studies involving 291,413 patients. Injury. 2009:40(7):692-7.

66. Zuckerman JD. Hip fracture. N Engl J Med. 1996;334(23):1519-25.

67. Melton $\perp$ 3rd. Hip fractures: a worldwide problem today and tomorrow. Bone. 1993;14(Suppl 1):S1-8.

68. Sambu N, Warner T, Curzen N. Clopidogrel withdrawal: is there a "rebound" phenomenon? Thromb Haemost. 2011:105(2):211-20.

\section{Publisher's Note}

Springer Nature remains neutral with regard to jurisdictional claims in published maps and institutional affiliations.
Ready to submit your research? Choose BMC and benefit from:

- fast, convenient online submission

- thorough peer review by experienced researchers in your field

- rapid publication on acceptance

- support for research data, including large and complex data types

- gold Open Access which fosters wider collaboration and increased citations

- maximum visibility for your research: over $100 \mathrm{M}$ website views per year

At $\mathrm{BMC}$, research is always in progress.

Learn more biomedcentral.com/submissions 